\title{
DRUMMOND EM HOLANDÊS O CACHIMBO DO POETA E O TABACO DO TRADUTOR
}

\section{Arie Pos}

Segundo uma notícia recente, "Holanda redescobre Drummond”. ${ }^{1}$ De Janeiro a Abril de 2009, o grupo de teatro Flint percorreu o país com um espectáculo intitulado Midden op de weg (No meio do caminho), baseado em poemas de Carlos Drummond de Andrade. E entre Novembro de 2008 e 15 de Fevereiro de 2009, o violonista flamenco Eric Vaarzon Morel e o actor Gijs Scholten van Aschat apresentaram em umas quarenta cidades holandesas o “duelo de música e palavras no palco" chamado Duende Saudade, a partir de poesia de García Lorca, Fernando Pessoa e Drummond.

A bem dizer, trata-se de uma segunda redescoberta, datando a primeira dos anos noventa, altura em que De liefde, natuurlijk (1992), tradução da autoria de August Willemsen do conjunto de poemas eróticos postumamente publicado O amor natural, fazia furor, servindo à cineasta Heddy Honigmann de inspiração para o seu documentário muito aplaudido O amor natural (1996). Em 1998, Willemsen publicou a sua tradução de Farewell e outro tradutor, Piet Janssen, publicou o livro de prosa Verhalen van een nieuweling (Contos de aprendiz).

Porém, a verdadeira descoberta de Drummond como um grande mestre da poesia mundial data de 1980 e deve-se, tal como a primeira e a segunda redescoberta, ao génio e empenho do tradutor August Willemsen (1936-2007) que, como professor universitário, tradutor, ensaísta e comunicador, abriu os olhos do público leitor para a literatura brasileira, até então quase totalmente desconhecida na Holanda. A partir da segunda metade dos anos setenta, deu a conhecer grandes escritores brasileiros, inicialmente através de artigos em revistas literárias e mais tarde através de esmeradas edições em livro, que ganharam fama não só pela qualidade das traduções mas igualmente pelos excelentes posfácios que, para além de uma introdução à obra e ao autor, proporcionavam um enquadramento literário baseado numa vasta bibliografia bem actualizada. Através da qualidade e autoridade das edições, conseguiu colocar "em grande” no mapa literário holandês, entre outros, Machado de Assis, Graciliano Ramos,

\footnotetext{
${ }^{1}$ Ver notícia de 09-02-2009 em http://www.parceria.nl/cultura/20090206-ct-drummond.
} 
João Guimarães Rosa e Dalton Trevisan. Em edições mais modestas, deu a conhecer os poetas Manuel Bandeira e João Cabral de Melo Neto. Porém, o maior sucesso veio com a grande antologia bilingue simplesmente intitulada Gedichten (Poemas, 1980) de Carlos Drummond de Andrade, editado no mesmo formato marcante ${ }^{2}$ (quase quadrado, $20 \times 21 \mathrm{~cm}$, e ilustrado) que uma antologia anterior (Gedichten, 1978) do português Fernando Pessoa - que teve um impacto estrondoso, celebrizando o poeta e o tradutor da noite para o dia e resultando na edição posterior da "obra completa" de Pessoa, também da mão de Willemsen. Com as antologias de Drummond e Pessoa obteve, em 1983, o mais importante prémio holandês de tradução, o Martinus Nijhoffprijs. Desde então, o nome de Willemsen está inevitavelmente ligado aos de Pessoa e Drummond, não sendo raras as vezes que, na Holanda, o mineiro e o lisboeta vêm referidos fraternalmente em confissões do género “de modo geral, não gosto de/não leio/não percebo poesia, mas adoro Pessoa e Drummond”. Porquê? Pela simplicidade e clareza da linguagem que usam para expressar a complexa condição humana.

Foram a mesma simplicidade e clareza que atraíram Willemsen quando, como estudante de português, começou a ler Pessoa, e quando, em 1967, a estudar literatura brasileira em São Paulo, travou conhecimento com Drummond, Bandeira e Cabral. Aborrecido com a linguagem literária floreada e rebuscada de muitos autores portugueses, suspirou de alívio: tinha encontrado poetas que escreviam como se fossem seres humanos (Willemsen, 2008: 70). Foi um amor à primeira vista e para toda a vida. Começou a traduzi-los para ver como "soavam" em holandês. Assim, nasceu o projecto de sonho de qualquer tradutor: o privilégio de poder traduzir os escritores de que gosta e com que sente uma grande afinidade. Willemsen tornou-se um tradutor apaixonado, divulgando os “seus” autores com um entusiasmo contagiante.

No que se segue, proponho-me esclarecer um pouco o segredo da simplicidade e clareza nas traduções que Willemsen apresentou na antologia, publicada ainda durante a vida de Drummond, que manteve contactos com o antologista e que cedeu para ilustração da contracapa do livro uma versão manuscrita do poema “A palavra”, na altura inédito e publicado em 1980 em A paixão medida.

\footnotetext{
$2 \mathrm{O}$ formato largo foi escolhido para evitar que fossem truncados os versos mais compridos do poema “Tabacaria” (cf. Willemsen, 2008: 219).
} 
Para os poemas até 1973, Willemsen baseou a sua escolha na edição de 1973 da Poesia completa e prosa (1. ${ }^{a}$ ed. 1964) e na sétima edição (1973) da Antologia Poética (1. ${ }^{\text {a }}$ ed. 1962), completando a selecção com poemas de As impurezas do branco (1973) e da segunda edição aumentada (1978) de Discurso de primavera e algumas sombras (1. ${ }^{\text {a }}$ ed. 1977). Dos 63 poemas da antologia, 31 foram também escolhidos por Drummond para a Antologia Poética.

Antes de vermos alguns poemas mais de perto, importa abordar uma questão que já em si poderia ser de algum modo decisiva para a impressão de simplicidade e clareza causada em tantos leitores holandeses da antologia. É o facto de o próprio tradutor ter tido a consciência de que muitos dos autores que optou por traduzir terem um estilo conciso e depurado e serem pouco dados à retórica da palavra. Tanto como os autores traduzidos, o tradutor é mais adepto da palavra certa do que da palavra bela, preferindo uma linguagem clara e "nórdica” ao poetizar e embelezar do estilo literário latino. Chama logo a atenção a sua predilecção pelos autores mais austeros do modernismo e pelo estilo depreciativamente caracterizado de “calvinista” de Machado de Assis. Willemsen considerava a sua escolha de autores "tipicamente calvinista” (Willemsen, 1994: 184), o que pode esclarecer, pelo menos em parte, o interesse que as suas traduções despertaram junto do leitor holandês, também ele pouco dado à linguagem ostensivamente poética e bela. A melancolia, o humor e a ironia, a aversão de grandes sentimentos e de efusões líricas, a discreta mestria formal, a linguagem sugestiva em vez de explicativa, tudo isto, tão tipicamente drummondiano, coadunava-se com o gosto do tradutor e do leitor.

Sendo assim, o material em si, portanto, já ia ao encontro da receptividade literária do público. Por outro lado, as ideias de Willemsen sobre a tradução favoreciam igualmente uma linguagem clara e concisa e denotavam uma aversão ao poetizar e embelezar de textos vertidos para a sua língua materna. Para ele, isso resultava em má poesia e acarretava o perigo de o tradutor se querer armar em poeta - poeta menos que medíocre, entenda-se. O que importava para Willemsen era captar e reproduzir a poesia do poema original, o que implicava um estudo profundo da forma, da escolha de palavras, dos significados e dos efeitos poéticos (organização do poema e dos versos, figuras de estilo, efeitos sonoros, rítmicos e visuais) - estudo esse que não só contemplava o aspecto técnico do verso, mas igualmente aspectos linguísticos, literários, sociais e culturais do poema e do restante obra do autor. 
Tudo isso contrariava a ideia de que a poesia "livre”, libertando-se da tradição da sintaxe poética, das formas fixas e dos ritmos e rimas regulares, fosse fácil de traduzir. Willemsen tinha plena consciência de que caracterizar a poesia de Drummond superficialmente como "verso livre” não era nenhuma autorização para traduzir "livremente”. Citou as palavras de T.S. Eliot, “The so-called vers libre which is good is anything but 'free'” (Drummond, 1980: 268), para chamar a atenção para o aperfeiçoado domínio formal e o refinamento estrutural de Drummond. Frisou igualmente a diferença entre a poética tradicional e o concreto, o prosaico, o antilírico e o antirretórico em Drummond. Eram aspectos em que a poesia drummondiana se aproximava de desenvolvimentos importantes na poesia holandesa do período 19201940, o que pode ser considerado mais um factor na receptividade do público leitor. Também a afinidade que Willemsen sentia com a obra de Drummond, Bandeira e Cabral tinha a ver com grandes nomes da poesia holandesa desta época: Bloem, Nijhoff, Slauerhoff, Achterberg (Willemsen 1994: 144), autores com uma sensibilidade moderna e modernista, uma linguagem depurada e um domínio formal que partia da versificação clássica para formas novas.

No entanto, se bem que as várias receptividades - “calvinista”, de linguagem e poética - tenham sido indubitavelmente factores na recepção positiva, mais decisivo parece ter sido a “drummondidade” que a poesia de Drummond trazia. E aí entra o génio e o talento do tradutor que se dá a devida conta de uma certa proximidade explorável entre as linguagens e formas poéticas na língua de partida e de chegada, mas que ao mesmo tempo tenta manter-se fiel ao original e explorar ao máximo o que é diferente e característico. Se calhar, a maior proeza do tradutor foi exactamente reconhecer e conseguir transmitir a voz e a "drummondidade" dos poemas com um respeito leal pelos originais. De modo algum isso quer dizer que o tradutor fosse um copiador subserviente, antes pelo contrário: fazia pleno uso da sua liberdade e imaginação, mas sempre a serviço do poeta que traduzia.

$\mathrm{Na}$ escolha dos poemas para a antologia havia obviamente elementos subjectivos. Justificando a sua escolha, Willemsen explica que levou em conta a divisão temática que o poeta fez na Antologia poética, mas que não procurou uma representação proporcional dos grupos temáticos (Drummond, 1980: 267-268). Tentou antes fazer uma escolha representativa de poemas de cada um dos livros individuais, chegando a uma certa intersubjectividade através da comparação das suas escolhas com outras antologias, traduções e poemas comentados em estudos sobre o autor. Para além da 
representatividade, usou como critério a traductibilidade, critério igualmente subjectivo e que, por enquanto, o obrigou a uma notável omissão. Embora reconhecendo a relatividade do critério da traductibilidade, havia limites. Por vezes, devido à própria natureza das duas línguas, o tradutor deparava com a impossibilidade objectiva de manter em tradução um mínimo de poesia (som e ritmo), obrigando-o a excluir o poema - ou até quase toda uma temática bem característica do autor: o amor. Pode parecer sacrilégio, mas Willemsen teve a ousadia de excluir poemas de amor por considerar intraduzível o belo trocadilho "amar amaro”, título da secção dedicada ao amor na autoantologia de Drummond e de um poema da mesma secção. Para além disso, embirrava com as traduções possíveis do verbo "amar”: "beminnen” (solene, arcaico e poético e, ainda por cima, com o segundo significado "fazer amor”), “liefhebben” (verbo composto separável: prefixo "lief” + verbo "hebben”, que em conjugação obriga à separação de prefixo e verbo, colocando problemas ao tradutor: "amo a filha do padeiro" - “ik heb de dochter van de bakker lief”). Em holandês, a forma mais corrente é "houden van" (verbo + preposição), parecido com "gostar de”, portanto, mas com a particularidade própria destes verbos compostos em holandês de verbo e preposição trocarem de posição na oração subordinada - outro desespero do tradutor de poesia.

Só anos mais tarde, Willemsen publicou um artigo onde resolveu os dois problemas de forma brilhante. ${ }^{3}$ “Amar amaro” ficou na história como a aparente sabedoria popular "Liefde is lastig” (O amor é complicado), uma expressão concisa bem ritmada com uma bela aliteração que cai no ouvido como se sempre tivesse existido, veiculando ao mesmo tempo uma suave ironia, uma certa resignação e carinho pelo amor. No artigo, o tradutor apresentou igualmente a sua tradução do poema "Quadrilha" (“João amava Teresa que amava Raimundo...”):

\section{Quadrille}

Jan hield van Treesje die van Rutger hield die van Maria hield die van Johannes hield die van Lily hield die van niemand hield.

Jan ging naar Amerika, Treesje naar het klooster,

Rutger kwam om bij een ongeluk, Maria werd een oude vrijster, Johannes pleegde zelfmoord en Lily trouwde met de heer J.P. Flipse die niet in het stuk was voorgekomen.

(Willemsen, 1987: 16)

\footnotetext{
3 “Liefde is lastig”, mais tarde incluído no volume de ensaio De taal als bril (1987: 13-18).
} 
Optou, portanto, pelo verbo "houden van" que na terceira pessoa do passado é "hield van”. O efeito da inversão na oração subordinada deixa-se reproduzir “à letra” num português "aproximativo":

João gostava de Teresa que de Raimundo gostava que de Maria gostava que de Joaquim gostava que de Lili gostava que de ninguém gostava.

Em holandês, o poema tem uma naturalidade perfeita muito próxima do original, também graças aos nomes neerlandizados. A repetição da ordem sintáctica - sujeito, verbo, complemento directo que a seguir se torna sujeito - sofreu uma alteração devido à inversão na oração subordinada, mas mantém o seu efeito de paralelismo enumerativo, que parece ser acentuado pelo efeito sonoro da construção repetida “die van ... hield”. A mesma assonância compensa a perda da aliteração na negação dupla "que não amava ninguém” em "die van niemand hield”, onde "niemand” ("ninguém”) constrói um paralelismo que não existe no original: a palavra funciona como se fosse o nome de uma pessoa, tal como nas orações anteriores.

O caso é um bom exemplo da maneira de trabalhar do tradutor. Willemsen mostra-se extremamente exigente na reprodução da naturalidade e dos efeitos poéticos, rejeitando o que considera não estar à altura do original e insistindo na procura da melhor solução que, neste caso, levou anos e anos, o que no entanto pode ser considerado algo extremo. No mesmo artigo, apresentou igualmente a sua tradução do poema “Amar amaro” e com a tradução de $O$ amor natural redimiu-se magistralmente do seu pecado por omissão relativo aos poemas de amor.

Os poemas de Gedichten denotam um mesmo esmero na reprodução da palavra certa e das qualidades poéticas do original, sempre à procura de uma naturalidade enganadoramente fácil e espontânea. Embora seja difícil elaborar uma lista de prioridades estratégicas do tradutor com base nas traduções - de certo modo, cada poema impõe as suas próprias prioridades e grande parte do processo de tradução é difícil de exteriorizar - parecem existir alguns princípios básicos na abordagem, como, aliás, o próprio tradutor indicou em alguns artigos e entrevistas. ${ }^{4}$ Mostra-se muito fiel à estrutura do poema e à organização sintáctica do verso original, procurando mantê-las

\footnotetext{
4 Sobre a tradução de poesia, para além do artigo referido na nota anterior, "Hoe doe je dat nou?" (Willemsen, 1987: 31-47), acerca de várias versões de “Tecendo a manhã” de João Cabral de Melo Neto. Sobre a tradução em geral: “De vertaler vertaald” (Willemsen, 1994: 157-187).
} 
na medida do possível, sem forçar a naturalidade. Está igualmente atento ao número de sílabas do verso e aos efeitos rítmicos e sonoros. Porém, por muito que possam ser regras de boa prática, a observação destes princípios não basta para obter uma boa tradução. Essa depende em grande parte da sensibilidade linguística e poética do tradutor, da sua inventividade e da qualidade das suas soluções. As traduções de Drummond mostram a mestria do tradutor em todos estes campos, sendo comum o elogio que se lêem como se fossem criações originais.

A edição bilingue é um óptimo instrumento para explorar os artifícios de Willemsen e apreciar o seu rigor certeiro, musicalidade, inventividade e sentido poético. O rigor está bem patente na tradução de "No meio do caminho", onde o jogo com os dois elementos fixos ("no meio do caminho" e "tinha uma pedra”) segue rigorosamente o original. Em holandês, esse jogo é apenas possível graças ao primeiro verso que, de certo modo, justifica as deslocações nos versos seguintes. Se o poema tivesse começado com o verso "Tinha uma pedra no meio do caminho”, teria sido inevitável um sujeito provisório (em holandês “Er”, cf. alemão “es gibt” e francês “il y a”): “Er lag een steen midden op de weg.”, pois de outra maneira seria considerado forçado ou até um erro gramatical. Porém, uma vez que “Midden op de weg lag een steen” (No meio do caminho tinha uma pedra) é perfeitamente aceitável, o primeiro verso introduz os dois componentes que se deslocam nos versos seguintes. Havia outra complicação com o uso de "er": o sujeito provisório podia ser usado no primeiro verso, mas então o início adverbial da frase obrigaria a uma inversão de verbo e sujeito: "Midden op de weg lag er een steen.”, originando uma alternância "lag er”/“er lag” nos versos seguintes que estragaria a severidade arquitectónica do poema. Optando por maior rigor e simplicidade, o tradutor construiu um equivalente notável com os elementos, tal como no original, inalteráveis:

\section{Midden op de weg \\ Midden op de weg lag een steen lag een steen midden op de weg lag een steen midden op de weg lag een steen}

Nooit zal ik die gebeurtenis vergeten In het leven van mijn zo vermoeide netvliezen.

Nooit zal ik vergeten dat midden op de weg

$\underline{\text { lag een steen }}$

lag een steen midden op de weg 
midden op de weg lag een steen.

(Drummond, 1980: 24-25)

A sensibilidade poética, a musicalidade e o domínio formal têm, tal como nos poemas originais e nos poetas holandeses que serviram de referência ao tradutor, uma presença discreta, dissimulada pela aparente naturalidade das traduções. Os padrões rítmicos e os efeitos sonoros parecem estar perfeitamente integrados na "respiração" do verso. Uma respiração própria, diferente do original, mas que "bate certo" numa versificação cuidada e adequada, também em poemas longos de versos curtos, como "José" e “Carrego comigo”, e de versos mais compridos, como "Resíduo”, "Morte no avião”, "Versos à boca da noite”, “A máquina do mundo”.

É difícil explicar estes efeitos a quem não domina bem a língua holandesa sem recorrer a versões gravadas ou pautas musicais. Mas vou tentar dar um pequeno exemplo elucidativo: a última estrofe de "Confidência do itabirano" ("Bekentenis van de Itabiraan”).

\author{
Original: \\ Tive ouro, tive gado, tive fazendas. \\ Hoje sou funcionário público. \\ Itabira é apenas uma fotografia na parede. \\ Mas como dói! \\ Tradução: \\ Eens had ik goud, eens had ik vee, eens had ik grond. \\ $\mathrm{Nu}$ ben ik ambtenaar. \\ Itabira is nog slechts een plaatje aan de wand. \\ Maar hoe dat schrijnt! \\ (Drummond, 1980: 43)
}

Os padrões rítmicos parecem muito diferentes:

Tive ouro, tive gado, tive fazendas.

Hoje sou funcionário público.

Itabira é apenas uma fotografia na parede.

Mas como dói!

Eens had ik goud, eens had ik vee, eens had ik grond.

Nu ben ik ambtenaar.

Itabira is nog slechts een plaatje aan de wand.

Maar hoe dat schrijnt!

O paralelismo no primeiro verso foi acentuado na tradução por "Eens had ik" (Outrora tive) e pelo uso de três substantivos de apenas uma sílaba (goud - ouro; vee - 
gado; grond - terreno(s)). No segundo verso, “funcionário público” só podia ser traduzido com naturalidade pela palavra muito mais curta "ambtenaar", que teve o mérito de manter no segundo verso o vogal dominante no poema, o “a”, ainda por cima na sua versão curta ou fechada “a” e na sua versão comprida ou aberta "aa”. No terceiro verso, "fotografia" causava um problema porque em holandês mais corrente seria “foto”, sem a's portanto. No entanto, a sua forma mais curta parece ter sugerido a palavra “plaatje” (imagem) com “a” aberto. Se calhar, não é mera coincidência o terceiro verso em holandês em retroversão elíptica dar "Itabira é tão só imagem na parede”, que copia exactamente o padrão rítmico do holandês. Ainda no terceiro verso, chama a atenção a escolha de "wand” para "parede”. A palavra mais corrente seria “muur”, mas devem ter sido o "a” curto e o "nd” no fim que devem ter determinado o uso de "wand” (que significa também parede), criando uma correspondência sonora com "grond" no primeiro verso e "ambt-" no segundo. O quarto verso copia o efeito rítmico do verso original.

Para além da parte rítmica, a estrofe é também um belo exemplo da riqueza sonora da tradução. Mantendo não só o som dominante “a”, mas repartindo-o na alternância de a’s abertos e fechados, o tradutor aproveitava uma característica do tratamento dos vogais na poesia holandesa que também usou para o "e” (aberto em “eens” e “vee”; fechado em "ben” e "slechts”) e para o “i” (fechado em “ik” e aberto em “Itabira”). A meia rima "fazendas” - "parede” reproduziu em "grond” - "wand”, reforçando-a com o belo efeito cruzado de alternâncias de a's abertos e fechados em “ambtenaar” - “plaatje aan de wand”. De assinalar é também o efeito sonoro da consoante "g/ch" em "goud” e "grond” e em "slechts” e "schrijnt”. Por fim, ainda salientou o remate da estrofe e do poema com dois ditongos ("oe” e "ij”) que ainda não tinham aparecido na estrofe.

Embora os exemplos citados já possam servir de amostra suficiente da inventividade do tradutor, para finalizar convém chamar a atenção para uma categoria de "liberdades" bem característica do tradutor. Trata-se de casos onde o leitor minimamente bilingue e menos avisado pode suspeitar à primeira vista de falhas ou até de erros de tradução. Raríssimas vezes, Willemsen aborda estas questões em notas onde explica o problema e a solução que escolheu. Na antologia de Drummond, apenas uma nota assim aborda os problemas de tradução do famoso poema "Isso é aquilo" ("Dit is dat”), um autêntico quebra-cabeças para o tradutor onde quase cada verso mereceria uma nota. $\mathrm{O}$ jogo associativo com a forma e o som dos pares de palavras, por um lado, e 
o seu significado, por outro, é na esmagadora maioria dos versos intraduzível e exige muito da inventividade do tradutor que, em vez de traduzir, deve encontrar pares “equivalentes” para este, segundo o tradutor, “inventário tanto lúcido como lúdico de procedimentos poéticos que acaba no sussurrar do silêncio, no sonoro nada de Mallarmé” (Drummond, 1980: 238) que é o poema. Após todo um estendal de “traduções” e “equivalentes” extremamente lúcidos e lúdicos que deixam o leitor perplexo a olhar da tradução para o original e do original para a tradução, Willemsen explica apenas um pouco da última estrofe (Drummond, 1980: 264-265): a manutenção da rima final "bombyx - ptyx”, o par “o cudelume Ulalume” e o par “o árvore a mar”. A troca do género do último par de palavras "reproduziu” através do verso "het was en de water", explicando na nota que se baseou numa troca do artigo neutro "het" com o artigo masculino ou feminino "de" do poeta holandês A. Roland Holst, que criticou o escritor de um romance intitulado Het wassende water (A água subindo) dizendo que logo o título estava mal, pois toda a gente sabia que não se dizia "het was en de water" (o roupa e o água) mas sim “de was en het water” (a roupa e a água).

A nota mostra mais uma vez como o tradutor encarava a tradução: exigia que estivesse à altura do original e que tivesse pernas para andar sem notas explicativas. Assim, a nota sobre o género das duas palavras parece mais uma questão de direitos de autor do que outra coisa. As soluções não raras vezes magistrais das nove estrofes anteriores tiveram de sobreviver sem explicações, deixando o juízo de valor ao leitor. Este pode encontrar verdadeiras jóias de inventividade na tradução, como é o caso da tradução do segundo verso da segunda estrofe “o ditirambo o cachimbo" para "de villanelle de van nelle” (Drummond, 1980: 182-183), onde o género poético “ditirambo" é substituído pelo género da "vilanela” e o “cachimbo" se transforma num cigarro de tabaco de enrolar da marca bem holandesa "Van Nelle".

O cachimbo do poeta e o tabaco do tradutor. De certo modo, Drummond tornouse holandês nas traduções de Willemsen e o tradutor proporcionou ao leitor holandês o mesmo encontro apaixonante com a obra de um poeta desconhecido que ele próprio viveu, em 1967, em São Paulo. Apesar de todos os factores de receptividade referidos, que sem dúvida predispuseram o tradutor e o leitor a um acolhimento favorável da poesia de Drummond, terá sido este encontro que foi e continua a ser a chave do sucesso em holandês. Só consigo ler os poemas num punhado de línguas, mas quanto a mim as traduções holandesas são, de longe, as melhores que conheço. 


\section{Referências}

DRUMMOND DE ANDRADE, C. Gedichten. Keuze, vertaling en nawoord van August Willemsen, Amsterdam/Antwerpen, De Arbeiderspers, 1980.

WILLEMSEN, A. De taal als bril - in twintig stukken, Amsterdam, Synopsis, 1987.

WILLEMSEN, A. Het hoge woord. Beschouwingen en boutades, Amsterdam/Antwerpen, De Arbeiderspers, 1994.

WILLEMSEN, A. Braziliaanse brieven. 11. ${ }^{\text {a }}$ ed., Amsterdam/Antwerpen, De Arbeiderspers, 2008. (1. ed. 1985) 